\title{
Unexpectedly high levels of selfing in the Australian shrub Grevillea barklyana (Proteaceae)
}

\author{
DAVID J. AYRE, ${ }^{*}$ ROBERT J. WHELAN \& AMANDA REID \\ Department of Biology, University of Wollongong, Northfields Avenue, Wollongong, NSW 2522, Australia
}

\begin{abstract}
Experimental hand pollinations have revealed that the Australian proteaceous shrub Grevillea barklyana is fully self-compatible, although one study suggested that when both self- and outcross pollen were presented to different flowers on the same inflorescence significantly greater seed set resulted from the outcrossed flowers. This study used single-locus electrophoretic surveys of maternal plants and their progeny arrays to test the prediction that this apparent 'preference' for outcross pollen would produce high levels of outcrossing within natural populations. We found instead that plants within three of four populations were almost completely selfed. Outcrossing rates $(t)$ in each of these populations (based on the progeny arrays of a minimum of nine plants) ranged from $0.07 \pm 0.03$ to only $0.33 \pm 0.08$ and showed little variation among years, ranging from $0.07 \pm 0.03$ to $0.10 \pm 0.03$ for a population sampled in each of two breeding seasons. Furthermore, examination of the progeny arrays from plants in the most intensively studied population revealed virtually no exchange of genes between immediately adjacent plants. Three pairs of alternative homozygotes were near neighbours (separated by less than $2 \mathrm{~m}$ ) and yet detectable outcrosses comprised only seven of the 108 seeds sampled. In contrast, the fourth population of G. barklyana appeared highly outcrossed $\langle t=0.85 \pm 0.2)$ which is typical of the realized mating system reported for other Australian Proteaceae. These data show that the realized mating system may vary widely among populations and may often be less than optimal. The occurrence of very low outcrossing rates within some populations may reflect the presence of introduced pollinators or other disturbances.
\end{abstract}

Keywords: inbreeding, mate choice, mating system, pollination, selfing.

\section{Introduction}

There has been considerable recent interest in the variability and flexibility of plant mating systems (e.g. Schemske \& Lande, 1985; Knight \& Waller, 1987; Waller \& Knight, 1989; Holtsford \& Ellstrand, 1992) including the capacity of plants to vary their mating system through 'mate choice' (Willson \& Burley, 1983; Ayre \& Whelan, 1989; Becerra \& Lloyd, 1992). Plant species can select either self or outcross pollen via preor post-zygotic mechanisms and realized outcrossing rates may vary widely among populations and among individual plants (Waller \& Knight, 1989). Furthermore, experimental pollinations have now been used to show that in self-compatible, but predominantly outcrossing plants, outcross pollen produces larger and

*Correspondence. more vigorous seed than self-pollen (Stephenson \& Windsor, 1986; Johnston, 1992; Montalvo, 1992). The quality of outcross pollen may also vary such that there are optimal outcrossing distances (possibly different from the normal outcrossing distance) inferred from the distance between males and females which maximizes fruit set (Waser \& Price, 1989).

The importance and nature of mate choice should be a function of the quantity and diversity of the pollen genotypes which are naturally available to individual plants. Genetic quality will be a function of the heritability of fitness (Willson \& Burley, 1983) and outcrossed pollen may be favoured when fitness is positively correlated with offspring diversity. Many plants, especially colonizing or weedy species, are known to be almost obligately self-fertilized but few if any studies have demonstrated resultant inbreeding depression (Schemske \& Lande, 1985). Indeed, few 
studies have examined this question in detail (Charlesworth \& Charlesworth, 1987).

Trees and shrubs in many species of the Australian Proteaceae have a seemingly great potential for mate choice. They typically produce multiple inflorescences, each made up of hundreds of perfect flowers which are apparently only rarely pollen limited and yet fruit set is extremely low (Ayre \& Whelan, 1989). Self and outcross pollen are often transported by avian, marsupial and insect pollinators but self pollen is expected to predominate on stigmas (Wooller et al., 1983; Goldingay et al., 1991; Carthew, 1993; Vaughton \& Carthew, 1993). Within plants, inflorescences show a staggered pattern of maturation and pollinators do move between plants during foraging bouts. However, pollinators typically visit the many opened flowers on a mature inflorescence and move between inflorescences on a plant (Carthew, 1993). Nevertheless, the realized outcrossing rates reported for several species are all high (Scott, 1981; Carthew et al., 1988; Vaughton \& Carthew, 1993; Coates \& Sokolowski, 1992; S. M. Carthew et al., unpublished data) despite the fact that some of these species have at least limited selfcompatibility. Furthermore, although there is potential for mate choice there is little evidence of flexibility of mating systems or of inter-plant or inter-population variability in mating systems within the Proteaceae. However, Vaughton \& Carthew's (1993) work with Banksia spinulosa var neoanglica shows that mate choice can occur: a population of this highly self-compatible plant was highly outcrossed.

The woody perennial shrub Grevillea barlyana var. mackleayana (Proteaceae) is classified as 'rare and restricted' (McGillivray, 1993). It exists typically as a set of small and apparently isolated populations (each usually fewer than 20 plants) within the Jervis Bay region of N.S.W. Information about its life-history is incomplete and includes several apparent paradoxes. It is unusual, as a threatened plant, in that it appears to be a colonizer of disturbed areas. However, it lacks obvious adaptations for widespread dispersal and has both a restricted range and shrinking habitat (owing to urban development). Mate choice experiments conducted within single inflorescences have shown a slight but significant 'preference' for outcross pollen (i.e. selfand outcross pollen added to different flowers on an inflorescence) which may reflect the faster growth rates of outcross pollen tubes (Harriss \& Whelan, unpublished data). However, the levels of seed set from autogamy or experimental self- or outcross-pollinations of whole inflorescences are similar (F. Harriss \& R. J. Whelan, unpublished data; G. Vaughton, unpublished data). Although the small size of most populations and their isolation suggest that they may contain relatively little genetic diversity, the history of these populations is unknown and we do not know if selection favours genotypically diverse progeny.

The present study uses allozyme data to: (i) test for spatial variation in outcrossing rates among three small and one large population(s) of G. barklyana; (ii) test for temporal variation in outcrossing rates within one of these populations; and (iii) assess the fine scale pattern of gene flow by comparison of progeny arrays of neighbouring plants.

\section{Materials and methods}

\section{Description of populations and collection of seed}

Four populations were sampled: Abraham's Bosom $\left(35^{\circ} 00^{\prime} 31^{\prime \prime} \mathrm{S}, \quad 150^{\circ} 49^{\prime} 31^{\prime \prime} \mathrm{E}\right)$, Honeymoon Bay $\left(35^{\circ} 03^{\prime} 33^{\prime \prime} \mathrm{S}\right.$, $\left.150^{\circ} 46^{\prime} 29^{\prime \prime} \mathrm{E}\right)$, Gravel Pit $\left(35^{\circ} 07^{\prime} 43^{\prime \prime} \mathrm{S}\right.$, $\left.150^{\circ} 40^{\prime} 12^{\prime \prime} \mathrm{E}\right)$ and Elmoos Road $\left(35^{\circ} 08^{\prime} 18^{\prime \prime} \mathrm{S}\right.$, $150^{\circ} 41^{\prime} 20^{\prime \prime} \mathrm{E}$ ) (Fig. 1). These populations typically consist of small shrubs (less than $3 \mathrm{~m}$ ) on heathland or open woodland isolated by distances of at least $100 \mathrm{~m}$ from other populations or individual plants. The Abraham's Bosom and Honeymoon Bay populations are located $8 \mathrm{~km}$ apart on the northern side of Jervis Bay. The Elmoos Road and Gravel Pit populations are approximately $12-18 \mathrm{~km}$ to the south and are separated by $2.5 \mathrm{~km}$. These locations varied in soil type and drainage. The population at Honeymoon Bay differed from the others in that it consisted of large plants (more than $4 \mathrm{~m}$ ) which formed the understorey within a eucalypt woodland and the population was relatively large (hundreds of plants compared with 30-50).

Where possible, 20 seeds or more were collected from each of at least 10 maternal plants, within each of the four populations. Because inflorescences typically bear about two seeds, the collection was distributed among many inflorescences on each plant. These seeds were stored for up to 1 week at $4^{\circ} \mathrm{C}$ pending electrophoresis to infer maternal genotypes and to determine outcrossing rates. To obtain sufficient mature seed many plants were sampled on up to three occasions within a 3 month period during peak flowering seasons. For the Abraham's Bosom, Elmoos Road and Gravel Pit populations, all plants bearing sufficient seed were sampled. The plants sampled at Honeymoon Bay were a haphazard sample of that large population. Samples therefore broadly represent the genotypes present in seeds within a given year. Sampling was carried out at Abraham's Bosom in 1989 and 1990.

\section{Electrophoresis}

Initial screening of 25 loci revealed only two consistently scorable polymorphisms: leucyl proline peptidase 


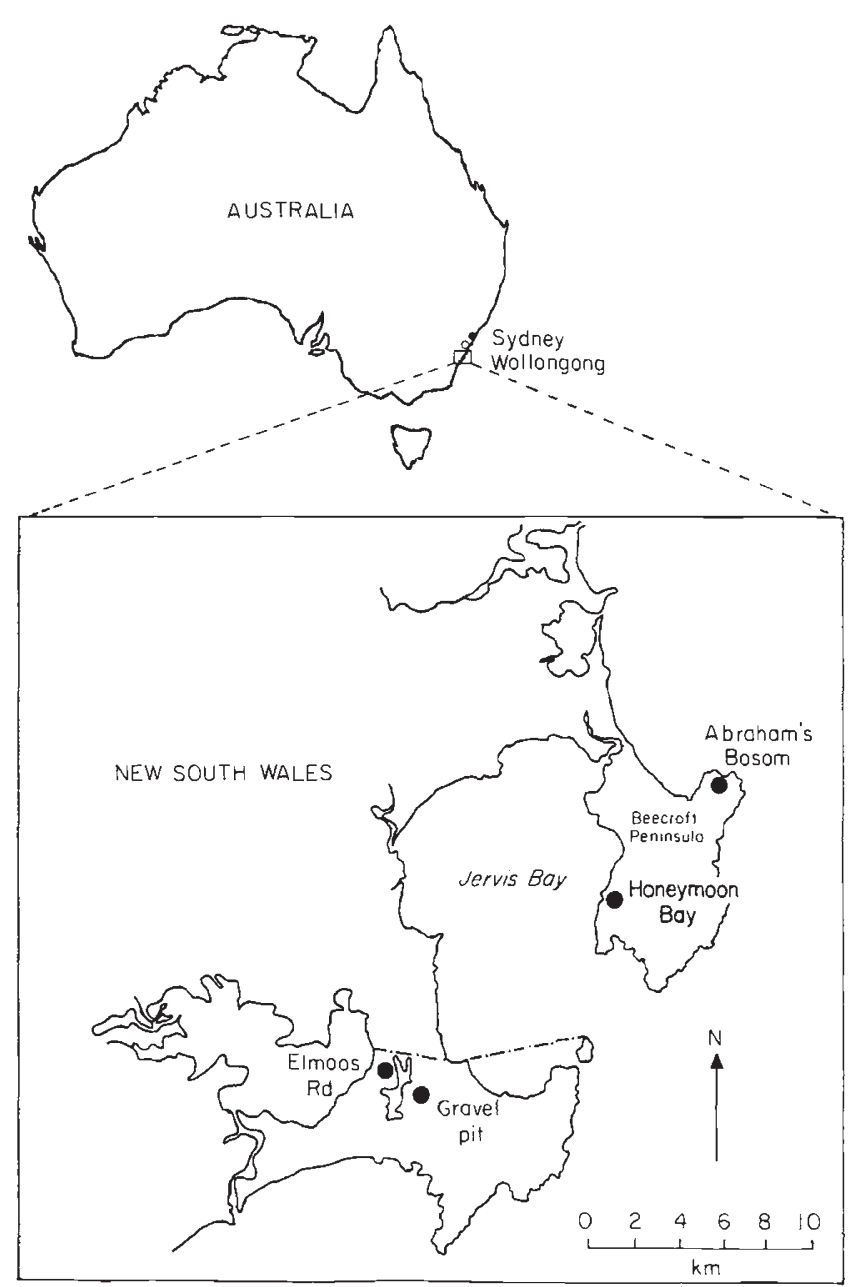

Fig. 1 Map showing location of the sampled populations of Grevillea barklyana within the Jervis Bay region of New South Wales.

$(L p p)$ and glucose phosphate isomerase $(G p i)$ within these populations. Staining methods were modified from Harris \& Hopkinson (1976). Initially all seed extracts were prepared in a simple extractant buffer $(10$ g sucrose, $20 \mathrm{mg}$ bromophenol blue, $0.1 \mathrm{ml} \mathrm{2-}$ mercaptoethanol $/ 100 \mathrm{ml}$ distilled water). However, the concentration of 2-mercaptoethanol was doubled to reduce satellite banding for Gpi. Lpp and Gpi were assayed on 12 per cent $\mathrm{w} / \mathrm{v}$ starch gels using buffers Nos 6 and 9 of Selander et al. (1971). Only one polymorphism could be consistently resolved within each of the sampled populations. Lpp (an apparent monomer) was scored for the Abraham's Bosom and Honeymoon Bay populations and Gpi (an apparent dimer) for the Elmoos Road and Gravel Pit populations. The two alleles detected within each population were labelled alphabetically in order of decreasing electrophoretic mobility.

\section{Analysis of data}

Genetic interpretations of zymograms, inference of maternal genotypes and estimations of outcrossing rates $(t)$, Wright's inbreeding coefficient $(F)$ and pollen allele frequencies were made from progeny arrays, assuming a mixed mating model as described by Brown et al. (1975). The significance of departures from expectations for panmixia were assessed by $t$-test, as described by Brown et al. (1975).

\section{Results}

Inspection of the genotype frequencies of the progeny of homozygous plants, within each of the four populations, revealed that detectably outcrossed seed-set occurred far less frequently than would be expected given equal segregation of alleles and random mixing of pollen (Table 1). Similar trends were apparent within each of the Abraham's Bosom (for both 1989 and 1990), Elmoos Road and Gravel Pit populations. These conclusions are based on Lpp in the Abraham's Bosom and Honeymoon Bay populations and on Gpi in the others. In total, only 52 heterozygous seed were collected from homozygous plants within those populations compared with 307 expected under panmixia. The Honeymoon Bay population was only marginally variable for $L p p$ but the $B B$ mothers still displayed only five of the 13 heterozygous progeny that would be expected for panmixia (Table 1).

The almost complete lack of heterozygous seed on homozygous plants (and hence detectably outcrossed seed) could reflect the restricted transfer of pollen within clumps of electrophoretically identical neighbours. However, we detected no obvious clustering of maternal genotypes within the Abraham's Bosom population (Fig. 2). Moreover, we detected extremely low levels of heterozygosity in the seed of those homozygous plants with near neighbours (less than $2 \mathrm{~m}$ apart) which were homozygous for the alternative allele. Specifically, plants 5 and 12, 1 and 30 and 9 and 14 yielded only seven heterozygous seeds compared with $44 A A$ and $57 B B$ seeds. Hence, it is clear that successful cross-pollination had been rare even when plants were separated by the shortest distances.

Maximum likelihood estimates of pollen allele frequencies within each population were highly variable (Table 2). Pollen allele frequencies within the 1989 cohort of seed from Abraham's Bosom could not be estimated via the maximum likelihood approach because there were no heterozygous progeny for the $B B$ maternal plants. These plants displayed similarly great heterogeneity of pollen allele frequencies among maternal genotypes (Table 1). However, these values 
Fig. 2 Map showing distribution of Lpp genotypes within an isolated population of the shrub Grevillea barklyana in the Abraham's Bosom nature reserve. Ovoids indicate the approximate size and shape of each plant.
Table 1 Comparison of observed genotype frequencies of progeny of $N$ homozygous or heterozygous mothers with expectations given equal segregation of alleles and complete outcrossing via randomly dispersed pollen, within each of four populations of the shrub Grevillea barklyana

\begin{tabular}{|c|c|c|c|c|c|c|c|}
\hline \multirow[b]{2}{*}{ Population } & \multirow[b]{2}{*}{ Year } & \multirow[b]{2}{*}{ Locus } & \multirow[b]{2}{*}{$N$} & \multirow{2}{*}{$\begin{array}{l}\text { Maternal } \\
\text { genotype }\end{array}$} & \multicolumn{3}{|c|}{ Genotypes of progeny } \\
\hline & & & & & $A A$ & $A B$ & $B B$ \\
\hline \multirow{6}{*}{$\begin{array}{c}\text { Abraham's } \\
\text { Bosom }\end{array}$} & \multirow[t]{3}{*}{1989} & \multirow[t]{3}{*}{$L p p$} & 5 & $A A$ & $86(53.6)$ & $6(38.4)$ & 0 \\
\hline & & & 4 & $A B$ & $29(15.1)$ & $21(28.5)$ & $7(13.4)$ \\
\hline & & & 3 & $B B$ & 0 & $0(31.8)$ & $60(28.2)$ \\
\hline & \multirow[t]{3}{*}{1990} & \multirow[t]{3}{*}{$L p p$} & 7 & $A A$ & $128(73.7)$ & $7(63.4)$ & 0 \\
\hline & & & 4 & $A B$ & $45(25.2)$ & $28(47.5)$ & $22(22.3)$ \\
\hline & & & 6 & $B B$ & 0 & $6(71.0)$ & $128(63.0)$ \\
\hline \multirow{3}{*}{$\begin{array}{r}\text { Elmoos } \\
\text { Road }\end{array}$} & \multirow[t]{3}{*}{1991} & \multirow[t]{3}{*}{$G p i$} & 2 & $A A$ & $43(12.8)$ & $1(31.2)$ & 0 \\
\hline & & & 3 & $A B$ & $14(8.2)$ & $24(28.0)$ & $18(19.8)$ \\
\hline & & & 7 & $B B$ & 0 & $18(39.1)$ & $116(94.9)$ \\
\hline \multirow[t]{3}{*}{ Gravel Pit } & \multirow[t]{3}{*}{1991} & \multirow[t]{3}{*}{$G p i$} & 6 & $A A$ & $85(69.8)$ & $11(26.2)$ & 0 \\
\hline & & & 4 & $A B$ & $27(25.1)$ & $29(34.5)$ & $13(9.4)$ \\
\hline & & & 1 & $B B$ & 0 & $3(5.7)$ & $18(15.3)$ \\
\hline \multirow{3}{*}{$\begin{array}{l}\text { Honeymoon } \\
\text { Bay }\end{array}$} & \multirow[t]{3}{*}{1991} & \multirow[t]{3}{*}{$L p p$} & 0 & $A A$ & 0 & 0 & 0 \\
\hline & & & 2 & $A B$ & $4(2.8)$ & $13(22.5)$ & $28(19.6)$ \\
\hline & & & 6 & $B B$ & 0 & $5(13.0)$ & $99(91.0)$ \\
\hline
\end{tabular}

Expected frequencies are given in parentheses.

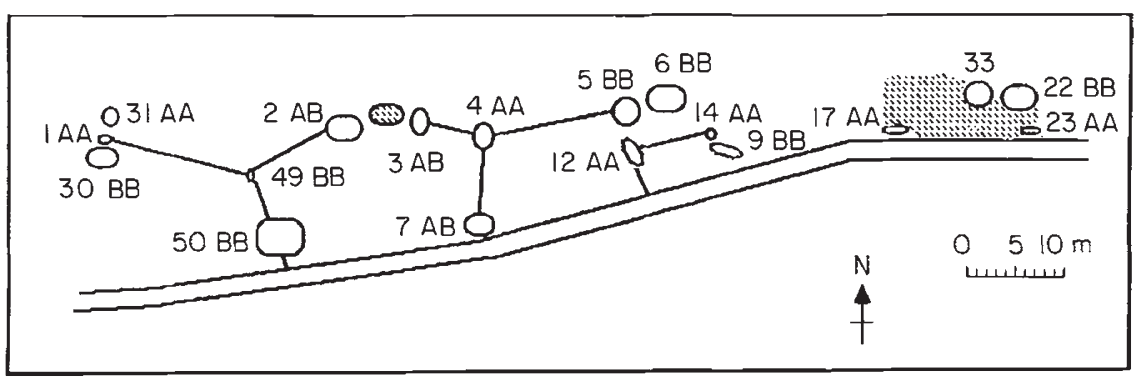

Table 2 Frequencies of the $A$ allele for progeny, maternal plants and pollen for groups of Grevillea barklyana plants collected from four populations in the Jervis Bay region of New South Wales, Australia

\begin{tabular}{|c|c|c|c|c|c|c|}
\hline \multirow[b]{2}{*}{ Population } & \multirow[b]{2}{*}{ Year } & \multirow{2}{*}{$\begin{array}{l}\text { No. of } \\
\text { plants } \\
\text { (seed) }\end{array}$} & \multirow[b]{2}{*}{ Locus } & \multicolumn{3}{|c|}{ Allele frequencies } \\
\hline & & & & Progeny & Mother & Pollen \pm S.E. \\
\hline Abraham's & 1989 & $12(209)$ & $L p p$ & 0.61 & 0.58 & N.A. \\
\hline Bosom & 1990 & $17(364)$ & $L p p$ & 0.53 & 0.50 & $0.54 \pm 0.13$ \\
\hline $\begin{array}{c}\text { Elmoos } \\
\text { Road }\end{array}$ & 1991 & $12(234)$ & $G p i$ & 0.33 & 0.29 & $0.17 \pm 0.13$ \\
\hline Gravel Pit & 1991 & $11(186)$ & $G p i$ & 0.72 & 0.73 & $0.67 \pm 0.10$ \\
\hline $\begin{array}{l}\text { Honeymoon } \\
\text { Bay }\end{array}$ & 1991 & $8(149)$ & $L p p$ & 0.09 & 0.13 & $0.06 \pm 0.10$ \\
\hline
\end{tabular}

N.A., could not be calculated as there are no $A$ alleles present in the progeny of $B B$ mothers. 
are derived from the genotype frequencies of mature seed and heterogeneity detected in the seed need not reflect heterogeneity within the real pollen pool.

Outcrossing rates within Abraham's Bosom, Elmoos Road and Gravel Pit populations were very low ranging from $0.07 \pm 0.03$ and $0.10 \pm 0.03$ at Abraham's Bosom to $0.33 \pm 0.08$ at the Gravel Pit (Table 3). The high degree of self-fertilization or inbreeding within these populations was reflected by large $F$ values which, with one exception, were similar to predicted equilibrium values, derived via the formula (Brown $e t$ al., 1975)

$F_{\mathrm{c}}=(1-t) /(1+t)$.

In contrast, the outcrossing rate calculated for the large Honeymoon Bay population $(t=0.85 \pm 0.20)$ was not significantly different from the value expected for panmixia, although this estimate of $t$ should be treated with caution as it is based on a single locus that was only marginally polymorphic (Table 2 ).

\section{Discussion}

An understanding of both optimal and realized mating systems is fundamental to the conservation of threatened plant populations and is especially relevant to estimates of the minimum population size and level of genetic diversity which needs to be maintained within breeding populations (Soulé, 1986; Hopper \& Coates, 1990). However, this study demonstrated that a realized mating system may be very different from that predicted from mate choice experiments and that the realized mating system may vary dramatically among populations. Interpopulation variation in mating systems is considered to be relatively common in plant species with mixed mating systems (Schoen,
1982). Such examples are relatively rare for Australian ecosystems (Carthew et al., 1988, Coates \& Sokolowski, 1992) but this may reflect the paucity of sufficiently replicated studies.

Within three populations of $G$. barklyana, the electrophoretic data indicated that seed-set was almost exclusively the result of positive assortative mating. This finding could reflect either preferential inbreeding (mediated by pre- or postzygotic mechanisms) or high levels of self-pollination. The latter explanation appears more likely as, in this study, pollen flow between immediately neighbouring plants was apparently minimal and studies in several populations have indicated that $G$. barklyana has equivalent seed set through autogamy and self- or outcross-pollen transfer (R. J. Whelan and D. J. Ayre, unpublished data; F. Harriss \& R. J. Whelan, unpublished data; G. Vaughton, personal communication). Furthermore, self-pollen transfer might be expected as most plants typically have at least several, and usually many, inflorescences flowering synchronously.

A high level of outcrossing, indistinguishable from random mating, was inferred for the large Honeymoon Bay population. This contrasts sharply with the results for the other populations and, if this difference were real, could reflect either genetic variation among populations or substantial variation in pollinator behaviour and hence pollen transfer. The present data do not allow us to distinguish between these hypotheses. Outcrossing may be more strongly favoured at Honeymoon Bay if the mating system of these plants has evolved within a persistently large population. It should be noted that inbreeding coefficients within this and other populations were close to values predicted at equilibrium and so do not suggest a recent history of colonization or bottlenecks. However, the population

Table 3 Single locus outcrossing rates $(t)$ and inbreeding coefficients $(F)$ estimated from arrays of approximately $20 \mathrm{seed} /$ plant for each of $n$ plants in three separate populations of the shrub Grevillea barklyana

\begin{tabular}{llllll}
\hline Population & Year & $n$ & $t$ & $F$ & $F_{\mathrm{e}}$ \\
\hline Abraham's & 1989 & 12 & $0.07 \pm 0.03^{* * * *}$ & $0.73 \pm 0.05^{* * * *}$ & $0.87^{* * *}$ \\
$\quad$ Bosom & 1990 & 17 & $0.10 \pm 0.03^{* * *}$ & $0.77 \pm 0.04^{* * *}$ & 0.82 \\
$\begin{array}{l}\text { Elmoos } \\
\quad 1991\end{array}$ & 12 & $0.16 \pm 0.04^{* * *}$ & $0.56 \pm 0.13^{* * *}$ & 0.72 \\
$\quad$ Road & & & & & \\
Gravel Pit & 1991 & 9 & $0.33 \pm 0.08^{* * * *}$ & $0.42 \pm 0.15^{* * *}$ & 0.50 \\
$\begin{array}{l}\text { Honeymoon } \\
\quad \text { Bay }\end{array}$ & 1991 & 8 & $0.85 \pm 0.20$ & $0.45 \pm 0.31$ & 0.08 \\
\hline
\end{tabular}

Predicted equilibrium inbreeding coefficients $\left(F_{\mathrm{e}}\right)$ were calculated as $F_{\mathrm{e}}=(1-t) /$ $(1+t)$. The significance of departures from $t$ values of one and $F$ and $F_{\mathrm{c}}$ values of zero was assessed by $t$-test.

$* * P<0.01,{ }^{* * *} P<0.001$. 
itself is atypical in many respects. It is not only large and extensive but contains unusually tall plants (typically more than $4 \mathrm{~m}$ compared with $2-3 \mathrm{~m}$ at all other sites examined) and occurs under a dense eucalypt canopy rather than forming part of a heathland or woodland canopy. These characteristics may favour unusual pollinator foraging strategies or attract a different set of pollinators.

The use of genetic data to infer mating systems rests on several assumptions. Most important are that (i) the loci used are selectively neutral, and (ii) the plants selected are representative of the population studied. Selective neutrality has not been verified in the present study. However, the inference of low outcrossing rates within three populations seems justified because similar results were obtained for each of two loci and the progeny derived from heterozygous maternal plants approximately conformed to Mendelian ratios. Furthermore, with the exception of Honeymoon Bay, the sampled plants represented the majority of the productive plants within each of these populations. Examined at the most simplistic level, these data therefore provide strong evidence that little detectable outcrossing had occurred in three populations whereas a high level of outcrossing would have been expected if there had been pollen movement between even adjacent plants.

As a self-compatible species, the outcrossing rate of $G$. barklyana appears suited to examination using the mixed mating model. However, this model requires the assumptions of panmictic movement of pollen among flowers and no inter-plant variability in outcrossing rates (Brown et al., 1985). These assumptions are virtually untestable and the violation of either would produce inter-plant variation in progeny allele frequencies as seen in this study. Violation of these assumptions should bias the estimate of $t$ downwards (Brown et al., 1985). Nevertheless, application of the model has revealed high levels of outcrossing in other Proteaceae (Scott, 1981; Carthew et al., 1988; Coates \& Sokolowski, 1992; Vaughton \& Carthew, 1993) and low $t$ values will still indicate a high level of selfing or inbreeding rather than random mating.

Our study suggests that the realized mating system within three or four studied populations differs from expectations based on the outcome of previous hand pollination experiments and observed pollinator movements. The earlier studies had indicated that outcross pollen is at least as likely to produce fruit as selfed pollen and that pollinator movements between plants are common. Nevertheless, plants appear to set predominantly selfed seed. High levels of inbreeding are often considered to be suboptimal for self-compatible species but this need not be true (Shields, 1982).
Indeed, the studied populations all occur within areas which have suffered moderate to severe human impacts: an old gravel quarry, a naval firing range and two partially cleared recreational reserves. Furthermore, all are contained within a larger area with mixed land use and large numbers of the exotic honey bee Apis mellifera which is a potential pollen thief (Taylor \& Whelan, 1988). Current mating systems may reflect this disturbance.

There are several reasons to believe that this species may be tolerant of high levels of inbreeding. Most of the studied populations were small and contained little allelic variation. Furthermore, this species has many characteristics of weedy species and is apparently a good colonist of disturbed areas. Successful outcrossing may always have been a rare event in most populations of this plant. Nevertheless, a great deal of work remains to be done, both within populations with high and low levels of realized outcrossing, to determine whether outcrossing does represent the optimal mating system for this species.

\section{Acknowledgements}

This work was supported by ARC grant no. A18715165 to RJW and DJA and the Australian Flora and Fauna Research Programme of the University of Woolongong. Seed were collected under permit No. JRLP 1 of the Australian National Parks and Wildlife Service. We thank Kerry Ayre, Alison Hunt, Sue Schibeci, Siegy Krauss and Glenda Vaughton for their critical reading of this manuscript. Darien Arthur and Julie Reid provided skilled technical assistance. This is publication no. 10b from the Ecology and Genetics Group of the University of Woolongong.

\section{References}

AYRE, D. J. AND WHELAN, R. J. 1989. Factors controlling fruit set in hermaphroditic plants: studies with the Australian Proteaceae. Trends Ecol. Evol., 4, 267-272.

BECERRA, $J$. X. AND LLOYD, D. G. 1992. Competition-dependent abscission of self-pollinated flowers of Phormium tenax (Agavavcea): a second action of self-incompatibility at the whole flower level? Evolution, 46, 458-469.

BROWN, A. H. D., BARRETT, S. C. H. AND MORAN, G. F. 1985. Mating system estimation in forest trees: models, methods and meanings. In: H. R. Gregorius (ed.) Genetics in Forestry, pp. 32-49. Springer-Verlag, Berlin.

BROWN, A. H. D., MATTESON, A. C. AND ELDRIDGE, K. G. 1975. Estimation of mating system of Eucalyptus obliqua L'Herit. by using allozyme polymorphisms. Aust. J. Bot., 23, 931-949.

CARTHEW, S. M. 1993. An assessment of pollinator visitation to Banksia spinulosa. Aust. J. Ecol. (in press). 
CARTHEW, S. M., AYRE, D. J. AND WHELAN, R. J. 1988. High levels of outcrossing in populations of Banksia spinulosa R.Br. and Banksia paludosa Smith. Aust. J. Bot., 36, 217-223.

CHARLESWORTH. D. AND CHARLESWORTH, B. 1987. Inbreeding depression and its evolutionary consequences. Ann. Rev. Ecol. Syst., 18, 237-268.

COATES, D. J. AND SOKOLOWSK1, R. E. S. 1992. The mating system and patterns of genetic variation in Banksia cuneata A.S. George. Heredity, 69, 11-20.

GoldingaY, R. L., CARTHEW, S. M. AND WHELAN, R. J. 1991. The importance of non-flying mammals in pollination. Oikos, 61, 79-87.

HARRIS. H. AND HOPKINSON, D. A. 1976. Handbook of Enzyme Electrophoresis in Human Genetics. North-Holland Publishing Co, Amsterdam.

HOLTSFORD, T. P. AND Ellstrand, N. C. 1992. Genetic and environmental variation in floral traits affecting outcrossing rate in Clarkia tembloriensis (Onagaraceae). Evolution, 46, 216-225.

HOPPER, S. D. AND COATES, D. J. 1990. Conservation of genetic resources in Australia's flora and fauna. Proc. Ecol. Soc. Aust., 16, 567-577.

JOHNSTON, M. O. 1992. Effects of cross and self-fertilization on progeny fitness in Lobelia cardinalis and L. siphilitica. Evolution, 46, 688-702.

KNIGHT, S. E. AND WALLER, D. M. 1987. The genetic consequences of outcrossing in the cleistogamous annual, Impatiens capensis. I. Population genetic structure. Evolution, 41, 969-978.

MCGILLIVRAY, D. J. 1993. Grevillea: revision of the genus Grevillea. Melbourne University Press, Melbourne.

MONTALVO, A. M. 1992. Relative success of self and outcross pollen comparing mixed- and single-donor pollinations in Aquilegia caerulea. Evolution, 46, 1181-1188.

SCHEMSKE, D. W. AND LANDE, R. 1985. The evolution of selffertilization and inbreeding depression in plants. II. Empirical observations. Evolution, 39, 41-52.
SCHOEN, D. J. 1982. The breeding system of Gilia achilleifolia: variation in floral characteristics and outcrossing rate. Evolution, 36, 596-613.

SCOTT; J. K. 1981. Estimation of outcrossing rate for Banksia attenuata R.Br. and Banksia menziesii R.Br (Proteaceae) Aust. J. Bot., 28, 53-59.

SELANDER, R. K., SMITH, M. H., YANG, Y. S., JOHNSON, W. B. AND GENTRY, J. B. 1971. Biochemical polymorphism and systematics in the genus Peromyscus. 1. Variation in the old-field mouse (Peromyscus polionotus). Stud. Gen. Soc. Austin, TX, 6, 49-90.

SHIELDS, w. M. 1982. Philopatry, Inbreeding and the Evolution of Sex. State University of New York Press, Albany.

STEPHENSON, A. G. AND WINSOR, J. A. 1986. Lotus corniculatus regulates offspring quality through selective fruit abortion. Evolution, 40, 453-458.

SOULE, M. E. 1986. Conservation Biology. Sinauer, Sunderland. TAYLOR. G. AND WHELAN, R. J. 1988. Can honeybees pollinate Grevillea? Aust. Zool., 24, 193-196.

VAUGHTON, G. AND CARTHEW, S. M. 1993. Evidence for selective abortion in Banksia spinulosa (Proteaceae). Biol. J. Lin. Soc. (in press).

WASER, N. M. AND PRICE、M. V. 1989. Optimal outcrossing in Ipomopsis aggregata: seed set and offspring fitness. Evolution, 43, 1097-1109.

WALLER, D. M. AND KNIGHT, S. E. 1989. Genetic consequences of outcrossing in the cleistogamous annual, Impatiens capensis. III. Interlocus associations. Heredity, 63, 1-9.

Willson, m. F. And Burley, N. 1983. Mate Choice in Plants: Tactics, Mechanisms and Consequences. Princeton University Press, Princeton, NJ.

WOOLLER, R. D., RUSSELL, E. M., RENFREE, M. B. AND TOWERS, P. A. 1983. A comparison of seasonal changes in the pollen loads of nectivorous marsupials and birds. Aust. Wildl. Res., 10, 311-317. 